\title{
Child pedestrian mortality and traffic volume in New Zealand
}

\section{Ian Roberts, Roger Marshall, Robyn Norton}

Department of Community Health, University of Auckland, Private Bag, Auckland, New Zealand Ian Roberts, $A C C$ training fellow in epidemiology, injury prevention research centre Roger Marshall, senior lecturer in biostatistics Robyn Norton, ACC senior fellow and director, injury prevention research centre

Correspondence and requests for reprints to: Dr Roberts.

$B M \mathcal{F} 1992 ; 305: 283$

Relation between child pedestrian death rates $(\bullet)$, traffic volume $(\mathbf{\square})$, and rates predicted by model $(\mathrm{O})$
Pedestrian injuries are a leading cause of childhood mortality. ${ }^{1}$ The analysis of trends in pedestrian death rates may provide information on the determinants of the incidence of these injuries. ${ }^{2}$ We have examined the relation between child pedestrian mortality and traffic volume in New Zealand from 1967 to 1987.

\section{Methods and results}

Child (aged $<15$ years) pedestrian death rates (ICD code E814.7) were calculated by using National Health Statistics Centre mortality data for 1967 to 1987 . A traffic volume index, based on data from traffic counters on urban highways throughout New Zealand, and the number of registered vehicles were obtained from the Ministry of Transport.

There was an annual average of 32.5 pedestrian deaths over the study period (3.7/100000 children yearly). From 1967 to 1975 there was a $57 \cdot 1 \%$ increase in traffic volume and a $69.7 \%$ increase in the death rate. Between 1975 and 1981 traffic volume increased by only $5 \cdot 2 \%$ and death rates fell by $46 \cdot 4 \%$. After 1982 traffic volume rose by $27 \cdot 6 \%$ and death rates by $53 \cdot 7 \%$ (see figure). The number or registered vehicles increased steadily by $91 \cdot 3 \%$ between 1967 and 1987 .

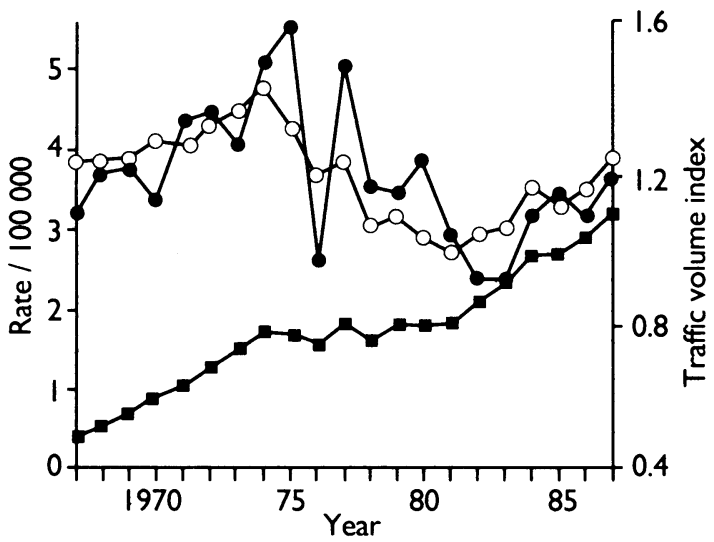

The trend in child pedestrian death rates was examined by Poisson regression modelling. ${ }^{3}$ Death rate was the dependent variable and traffic volume index $(\mathrm{V})$, number of registered vehicles $(\mathrm{R})$, and year $(\mathrm{Y})$ the explanatory variables. The expected death rate $(F)$ was modelled by a log linear equation, of the form: $\log F=\beta_{0}+\beta_{\mathrm{V}} \mathrm{V}+\beta_{\mathrm{Y}} \mathrm{Y}+\beta_{\mathrm{R}} \mathrm{R}$. After fitting the model only the variables $\mathrm{V}\left(\beta_{\mathrm{v}}=3.089\right.$, SE $\left.0.929 ; \mathrm{p}=0.0009\right)$ and
$\mathrm{Y}\left(\beta_{\mathrm{Y}}=-0.095\right.$, SE $\left.0.025 ; \mathrm{p}=0.0002\right)$ were significant. The number of registered vehicles $(R)$ was not significant in the model $(p=0 \cdot 244)$ or in a model with only $R$ and $Y(p=0 \cdot 102)$. When rates were modelled with the unusual year 1976 excluded the coefficients were essentially unchanged. The relation between the death rates, traffic volume, and rates predicted by the model are shown in the figure.

\section{Comment}

A definite decline in child pedestrian death rates occurred between 1975 and 1981, a period in which there was very little growth in traffic volume. The energy crisis of 1974, which was accompanied by a fourfold increase in the price of petrol, was probably important in retarding the growth in traffic volume. As a result of the crisis the New Zealand government introduced "carless days" (when each car was required to be off the road for one day each week) and a ban on weekend petrol sales, which lasted until August $1980 .{ }^{4}$ That the pedestrian death rates fell, as opposed to having levelled off in line with the plateau in traffic volume, suggests that the safety of the transport system was also improving during the period.

The results of modelling support these findings. A positive coefficient was derived for traffic volume, showing that death rates increase when traffic volume increases. A negative coefficient was derived for year, showing that, after controlling for traffic volume, death rates decline over time.

The impressive fall in death rates that occurred between 1975 and 1981 suggests that limiting the future growth in traffic volume has the potential significantly to reduce child pedestrian mortality. This would require public policy changes that strengthen the public transport system, discourage the use of private vehicles, promote cycling, and encourage the use of rail, river, and sea transport by freight. Ultimately the impetus for reducing the growth in traffic volume may come from an increasing awareness of the health effects of road traffic apart from injury. With cities in Britain, North America, and Australia having recently experienced episodes of photochemical pollution, the environmental effects of motorisation are increasingly becoming the focus of attention.

We thank Professor Robert Beaglehole for critical comments on the manuscript.

\footnotetext{
National Health Statistics Centre. Mortality and demographic data 1987. Wellington: Department of Health, 1990.

Rose Sick individals and sick populations. In I E pidemiol 1985;14:32-8. Fro G. Sick The analyis of racs using Poisson regression models. Biomet 1983;39:665-74.

Department of Statistics. New Zealand afficial yearbook 1990. Wellington: Department of Statistics, 1990

5 Read RC, Green M. Internal combustion and health. $B M F$ 1990;300:761-2.

(Accepted 8May 1992)
}

\section{Cardiac rehabilitation programmes: are women less likely to attend?}

\section{Beaumont Hospital \\ PO Box 1297, Dublin 9, Republic of Ireland Hannah M McGee, health psychologist John H Horgan, consultant cardiologist}

Correspondence to:

Dr McGee.

$B M \mathcal{F} 1992 ; 305: 283-4$

\section{Hannah M McGee, John H Horgan}

Cardiac rehabilitation programmes offer valuable secondary prevention after myocardial infarction and other cardiac events. Research attests to the effectiveness of rehabilitation programmes - for example, in decreasing death rates after myocardial infarction. However, the evidence is based almost exclusively on male patients under 70 . Though the positive impact of exercise training by female cardiac patients has been documented, ${ }^{2}$ women are perceived as being less motivated to attend structured programmes, especially those entailing vigorous exercise. ${ }^{3}$

Some studies have noted higher drop out rates for women. Oldridge and colleagues noted a higher one year drop out rate from a cardiac rehabilitation programme for female $(18 / 28 ; 64 \%)^{4}$ than male $(65 / 153$; $42 \%)^{5}$ patients after myocardial infarction or coronary artery surgery in the 1970s. A study of similar patients in the early 1980 s found a female drop out rate of $18.9 \%$ ( $v 7.9 \%$ in men) and a lower programme attendance record for women $(77 \% v 87 \%)(\mathrm{n}=37$ women, 227 men). ${ }^{2}$ 